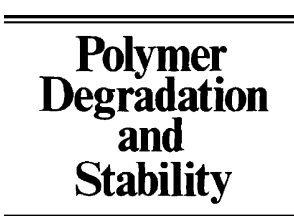

www.elsevier.com/locate/polydegstab

\title{
Thermal stabilisation of poly(vinyl chloride) by organotin compounds
}

\author{
E. Arkış*, D. Balköse \\ Izmir Institute of Technology, Chemical Engineering Department, \\ Gulbahce-Urla, Izmir, 35430 Turkey
}

Received 15 September 2003; received in revised form 6 February 2004; accepted 10 February 2004 Available online 11 November 2004

\begin{abstract}
The effect of LSN 117 (dioctyl tin bis isooctyl thioglycollate, an organotin compound) on the heat stability of plasticised PVC was investigated in this study. The organotin stabiliser had carbonyl and carboxylate groups and PVC contained traces of $\mathrm{Fe}, \mathrm{Zn}, \mathrm{Ca}, \mathrm{Cu}$ and $\mathrm{Sn}$. The heat stability of the films were tested at $140{ }^{\circ} \mathrm{C}$ and $160{ }^{\circ} \mathrm{C}$ or $180{ }^{\circ} \mathrm{C}$ by heating in an air circulation oven up to $2 \mathrm{~h}$ and by measuring $\mathrm{HCl}$ evolved using a Metrohm 763 PVC thermomat and by thermogravimetric analysis. The onset of $\mathrm{HCl}$ evolution was at 14.3 and $2.5 \mathrm{~h}$ at $140{ }^{\circ} \mathrm{C}$ and $160{ }^{\circ} \mathrm{C}$, respectively, for PVC film without LSN117. On the other hand, the film with LSN117 did not evolve $\mathrm{HCl}$ in $30.3 \mathrm{~h}$ at $140{ }^{\circ} \mathrm{C}$. $\mathrm{HCl}$ started to evolve from the films with LSN 117 in $14.3 \mathrm{~h}$ at $160{ }^{\circ} \mathrm{C}$. The TGA curve also indicated PVC film with LSN 117 degraded at higher temperatures than control films. LSN 117 was found to be a good heat stabiliser for plasticised PVC and it did not have any detrimental effect on mechanical properties.
\end{abstract}

(c) 2004 Elsevier Ltd. All rights reserved.

Keywords: Organotin; PVC heat stabilizer; Dehydrochlorination; Dioctyl phthalate

\section{Introduction}

Poly(vinyl chloride) (PVC) decomposes at a temperature lower than its processing temperature. It degrades by the loss of $\mathrm{HCl}$ at operating temperatures with the formation of conjugated double bonds. This can be prevented with heat stabilizers providing heat stability. Thermooxidative degradation of PVC can be blocked or

\footnotetext{
* Corresponding author. Tel.: +90 232 4986243; fax: +90 232 4986355.

E-mail address: esenarkis@iyte.edu.tr (E. Arkış).
}

retarded by metal soaps, epoxy compounds, phosphites, aliphatic and aromatic compounds and organotin compounds. Organotin stabilizers are mainly used in production of sheets, profiles, general purpose and potable water pipes, sidings, films, foils, bottles and articles meant for paper packaging.

During the thermal degradation of PVC, labile chlorine atoms start the reaction and speed up the $\mathrm{HCl}$ evolution. Tin thioglycollates reduce thermal degradation of PVC in two ways:

1. Labile chlorine atoms are substituted by $\mathrm{S}$ atoms and conjugated double bond formation is prevented: 


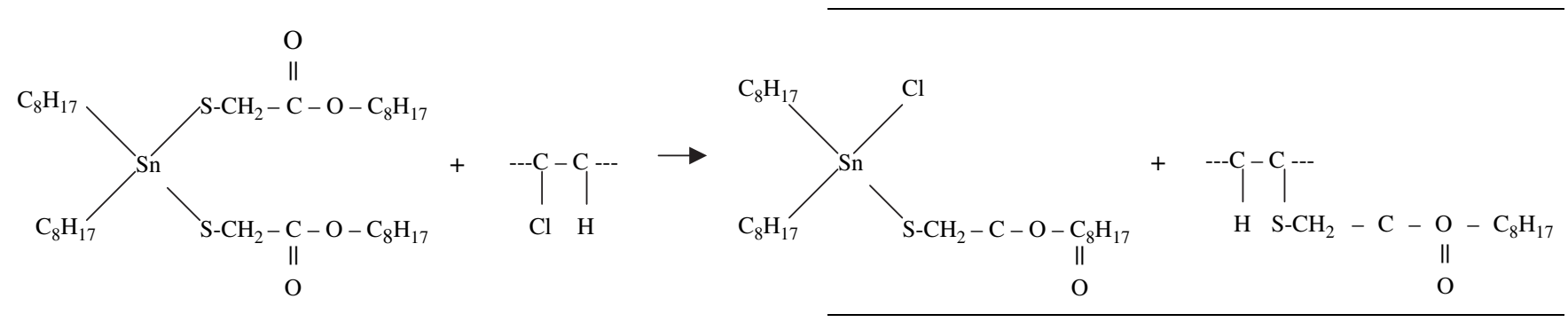

2. $\mathrm{HCl}$ which is evolved as a result of PVC degradation and speeds up the conjugated double bond formation, enters into the reaction by scavenging.

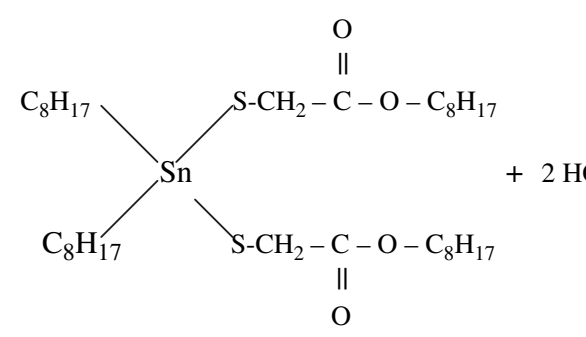

A tin stabiliser typically has three types of bonds, $\mathrm{SnC}$, $\mathrm{SnO}$ and $\mathrm{SnS}$ compared with only MO in metal soaps. The stability of $\mathrm{SnC}$ bonds is a crucial factor since any further reaction with $\mathrm{HCl}$ leading to formation of Lewis acid, $\mathrm{RSnCl}_{3}$ or $\mathrm{SnCl}_{4}$ would lead to very high degradation rate and catastrophic failure of the polymer. Facile cleavage of the $\mathrm{SnX}$ bond is a requisite for efficient reaction but it is equally important that the resulting CSn bond remains intact.

The order of reactivity of $\mathrm{X}$ groups is as follows: thioglycollate $>$ maleate $>$ laureate. In practice, organotin stabilizers are capable of decomposing peroxides and exhibit retarding effects [1]. Occupational Safety and Health Administration (OSHA) Threshold Limit Values (TLV) standard for exposure to all organotin compounds is $0.1 \mathrm{mg}$ tin for organotin compounds per $\mathrm{m}^{3}$ of air averaged over an 8-h work shift [2]. Garrigues et al. [3] have investigated thermal dehydrochlorination of dialkyltin carboxylates in PVC solution. Rujian et al. [4] showed that the higher the dibutyltin dilaureate content, the greater the concentration of shorter polyene sequences. We have previously studied PVC with Farstab Sn 500K (a liquid organotin stabilizer with $8 \%$ tin from Farstab stabilizer company, Turkey) [5]. Baltacioğlu and Balköse studied the effect of zinc stearate and epoxidized soybean oil on the thermal stability of emulsion type PVC [6].

The objective of the present study was to investigate the effect of another organotin compound, approved by the Food and Drug Administration (FDA), dioctyl tin bis isooctyl thioglycollate (LSN117), on the thermal stability of plasticised PVC.

\section{Experimental}

PVC (petvinyl P38/74) from Petkim, dioctyl phthalate (DOP) from Sankim and liquid organotin stabilizer (dioctyltin bis (isooctyl thioglycollate)) from Akdeniz Kimya were used in this study. Films were prepared from PVC (100 parts), DOP (60 parts) and LSN117 (2phr) by mixing at $25{ }^{\circ} \mathrm{C}$ and gelation at $140{ }^{\circ} \mathrm{C}$ for 15 min. Samples were tested for heat stability at $160-$ $180{ }^{\circ} \mathrm{C}$ for $15-105 \mathrm{~min}$ under forced convection air circulating inside the oven. PVC powder and the surface of the films with and without LSN 117 were investigated by energy dispersive X-ray analysis (EDX) using a Philips XL-305 field emission gun scanning electron microscope. Five points were investigated for each sample.

The transmission IR spectra of the films were taken using a Shimadzu FTIR 8601 PC infrared spectrophotometer with 40 scans per sample. Mass loss during heating of the films and DOP was measured by a DuPont thermogravimetric analyser (TGA) with heating at a rate of $10{ }^{\circ} \mathrm{C} \mathrm{min}{ }^{-1}$ from 30 to $250{ }^{\circ} \mathrm{C}$ under $40 \mathrm{~cm}^{3} \mathrm{~min}^{-1}$ nitrogen gas flow.

DSC curves of the films were obtained at a rate of $10{ }^{\circ} \mathrm{C} \mathrm{m^{-1 }}$ under $40 \mathrm{~cm}^{3} \mathrm{~min}^{-1}$ nitrogen gas flow using a Setaram DSC92 differential scanning calorimeter.

Dehydrochlorination of the films at $140{ }^{\circ} \mathrm{C}$ and $160{ }^{\circ} \mathrm{C}$ was determined in a Metrohm $763 \mathrm{PVC}$ thermomat (Fig. 1). The sample cut into $2 \mathrm{~mm} \times 2 \mathrm{~mm}$ size was placed in reaction vessels and put into the thermomat when the temperature reached the previously set value. When $\mathrm{N}_{2}$ gas passes over the sample in the heated 


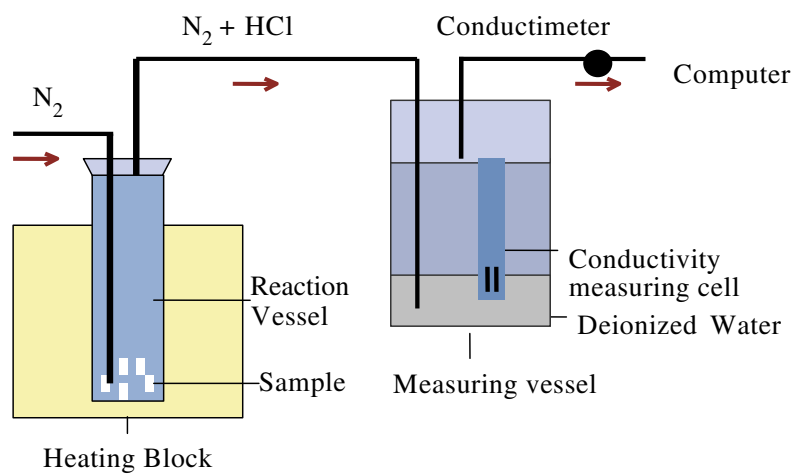

Fig. 1. Schematic diagram of the PVC Thermomat.

reaction vessel, evolved $\mathrm{HCl}$ is carried out and passes through a measuring vessel filled with deionised water. Conductivity of the solution in the measuring vessel versus time is measured by conductimeter and recorded by a computer.

Tensile strength and elongation at break were measured by Uzano 256 Shimadzu autograph from stress-elongation diagram of the films obtained at a rate

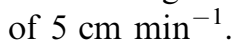

\section{Results and discussion}

\subsection{Characterization of LSN117 and films with or without LSN117}

The IR spectrum of the organotin stabilizer (Fig. 2) had $\mathrm{C}=\mathrm{O}$ group vibration at $1730 \mathrm{~cm}^{-1}$ and $\mathrm{COO}^{-}$ vibrations at 1380 and $1540 \mathrm{~cm}^{-1}$. Carboxylate groups were observed as well as the ester group of LSN117.

The EDX analysis of PVC powder and the surface of the films are reported in Table 1 giving quantitative information and standard deviation about the composition of the films. PVC powder had $42.40 \% \mathrm{C}, 13 \% \mathrm{O}$, and small quantities of $\mathrm{Sn}, \mathrm{Ca}, \mathrm{Fe}, \mathrm{Cu}$ and $\mathrm{Zn}$ which

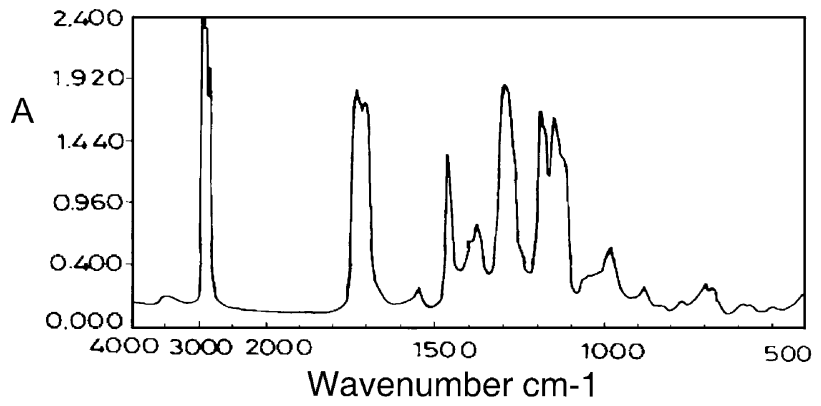

Fig. 2. IR spectrum of LSN117.

could be catalyst residues or could come from water used in PVC production.

No significant difference was observed in films with and without LSN117 with respect to Sn element. The small quantity of Sn added with LSN117 was out of the limits of sensitivity of the EDX analysis. The surfaces of the films were covered with DOP since $\mathrm{Cl}$ content at the surfaces was very low and $\mathrm{C}$ content (between $67.7 \%$ and $77.0 \%$ ) was very close to that of pure DOP which was $73.8 \%$ on hydrogen free basis.

\subsection{Volatility of dioctyl phthalate}

DOP is a plasticiser which lowers the glass transition temperature $\left(T_{\mathrm{g}}\right)$ and makes it flexible at room temperature. When plasticised films were heated, simultaneous plasticiser evaporation and thermal dehydrochlorination occurred. Differential scanning calorimetric curves of heated and unheated samples (Fig. 3) showed that the glass transition temperature of the unheated sample was $50{ }^{\circ} \mathrm{C}$. Onset and end temperatures were 37 and $62{ }^{\circ} \mathrm{C}$, respectively.

For the film heated at $180{ }^{\circ} \mathrm{C}$ for $105 \mathrm{~min}$, the glass transition temperature was found to be $80{ }^{\circ} \mathrm{C}$ and became closer to the glass transition temperature of pure PVC. Onset and end temperatures were 77 and $110{ }^{\circ} \mathrm{C}$, respectively: This indicates that DOP evaporated from

Table 1

EDX analysis of PVC-DOP and PVC film with LSN117

\begin{tabular}{|c|c|c|c|c|c|c|c|c|c|c|}
\hline \multirow[t]{2}{*}{ Element } & \multicolumn{2}{|l|}{$\begin{array}{l}\text { PVC } \\
\text { powder }\end{array}$} & \multicolumn{2}{|c|}{$\begin{array}{l}\text { PVC plastigel-DOP } \\
(15 \mathrm{~min})\end{array}$} & \multicolumn{2}{|c|}{$\begin{array}{l}\text { PVC plastigel-DOP } \\
(105 \mathrm{~min})\end{array}$} & \multicolumn{2}{|c|}{$\begin{array}{l}\text { PVC-DOP-LSN117 } \\
(15 \mathrm{~min})\end{array}$} & \multicolumn{2}{|c|}{$\begin{array}{l}\text { PVC-DOP-LSN117 } \\
(105 \mathrm{~min})\end{array}$} \\
\hline & Mass $(\%)$ & $\mathrm{SD}^{\mathrm{a}}$ & Mass $(\%)$ & SD & Mass $(\%)$ & $\mathrm{SD}$ & Mass $(\%)$ & $\mathrm{SD}$ & Mass $(\%)$ & SD \\
\hline $\mathrm{C}$ & 42.4 & 4.81 & 67.7 & 2.90 & 77.0 & 4.29 & 74.41 & 0.477 & 76.46 & 1.575 \\
\hline $\mathrm{O}$ & 1.1 & 0.19 & 10.2 & 0.82 & 11.0 & 0.96 & 24.22 & 0.336 & 21.90 & 1.472 \\
\hline $\mathrm{Cl}$ & 52.6 & 4.83 & 19.3 & 2.40 & 5.81 & 1.32 & 0.08 & 0.310 & 0.24 & 0.138 \\
\hline Sn & 0.57 & 0.16 & 0.29 & 0.12 & 0.29 & 0.16 & 0.13 & 0.108 & 0.39 & 0.213 \\
\hline $\mathrm{Ca}$ & 0.15 & 0.03 & 0.12 & 0.03 & 0 & 0 & 0.08 & 0.044 & 0.10 & 0.061 \\
\hline $\mathrm{Fe}$ & 0.52 & 0.15 & 0.36 & 0.15 & 0.80 & 0.21 & 0.35 & 0.142 & 0.32 & 0.090 \\
\hline $\mathrm{Cu}$ & 1.05 & 0.10 & 0.84 & 0.34 & 2.30 & 0.54 & 0.30 & 0.105 & 0.34 & 0.149 \\
\hline $\mathrm{Zn}$ & 1.55 & 0.30 & 1.15 & 0.33 & 2.86 & 0.65 & 0.42 & 0.146 & 0.25 & 0.190 \\
\hline
\end{tabular}

${ }^{\text {a }} \mathrm{SD}$, standard deviation. 


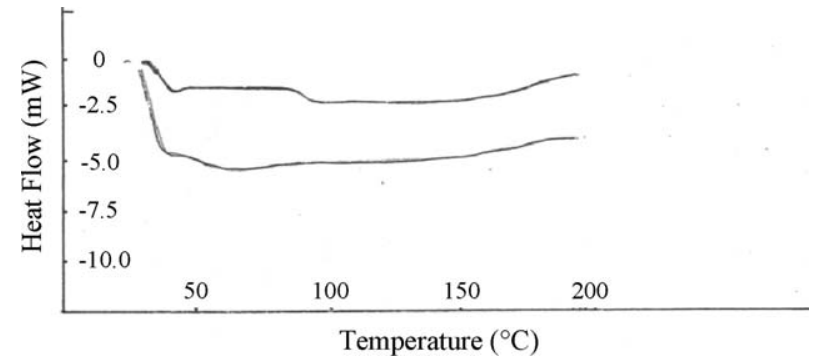

Fig. 3. DSC curves for PVC film with LSN117. (a) Unheated; (b) after heating at $180{ }^{\circ} \mathrm{C}$ for $105 \mathrm{~min}$.

the films causing increase in glass transition temperature.

\subsection{Diffusion of DOP in PVC}

DOP was volatile as seen by DSC analysis and in the TGA curve of DOP in Fig. 4. In Fig. 5, which shows the IR spectra of films heated for different periods at $160{ }^{\circ} \mathrm{C}$, the absorbance values for the aromatic ring vibrations of DOP at 1580 and $1600 \mathrm{~cm}^{-1}$ decreased in intensity confirming the evaporation of DOP from the films. Its rate of evaporation from PVC films was expected to be controlled by the rate of diffusion in the films. DOP diffusion coefficients $(D)$ in the films were estimated from IR spectra of the films according to the following equation:

$D=\left(M_{t} / M_{\infty}\right) \times(L / 4)^{2} \times(\pi / t)$

where $M_{\infty}$ is mass evaporated at equilibrium, $M_{t}$ is mass evaporated at time $t, t$ is time in seconds and $L$ is film thickness in meters.

Defining $A_{0}, A_{t}$ and $A_{\infty}$ from IR curves as the peak absorbances of DOP for unheated films and films heated

TGA

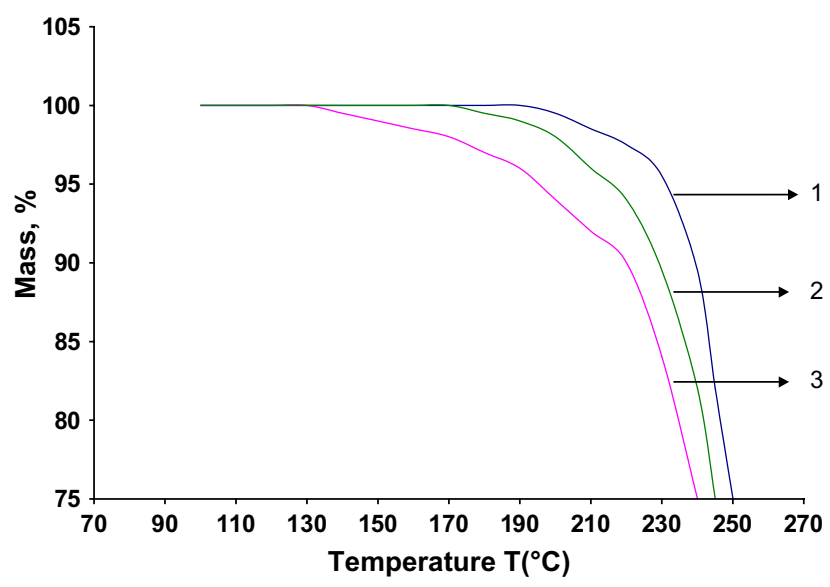

Fig. 4. TGA curves for (1) PVC film with LSN117, (2) DOP liquid, (3) control PVC-DOP film without LSN.

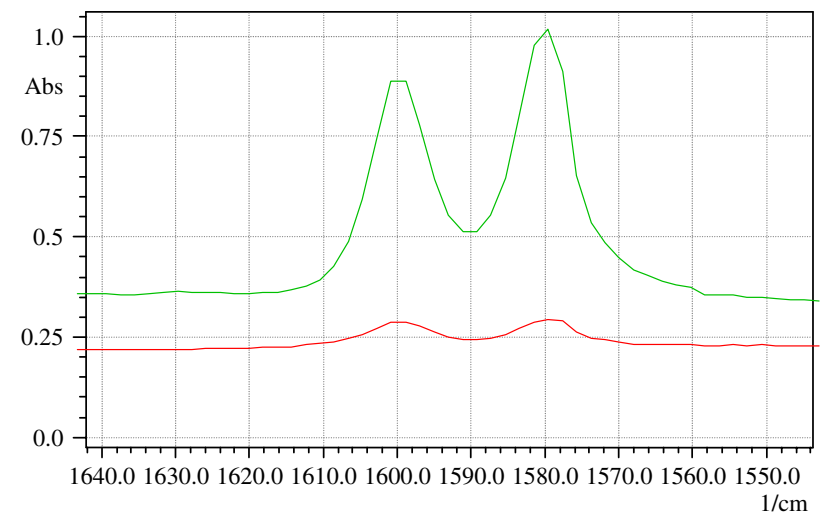

Fig. 5. IR spectrum of PVC films with LSN117. Upper curve, unheated; lower curve, heated at $180{ }^{\circ} \mathrm{C}$ for $105 \mathrm{~min}$.

for time period $t$, and equilibrium time period, respectively, the following equation is obtained:

$\left(M_{t} / M_{\infty}\right)=\left[\left(A_{0}-A_{t}\right) /\left(A_{0}-A_{\infty}\right)\right]$

$A$ values can be read from the 1580 and $1600 \mathrm{~cm}^{-1}$ peaks which are characteristic of DOP (Table 2).

Assuming all DOP evaporates at equilibrium at $160{ }^{\circ} \mathrm{C}\left(A_{\infty}=0\right)$, DOP diffusion coefficients of PVC films with LSN117 were determined as $1.63 \times 10^{-15}$ $\mathrm{m}^{2} \mathrm{~s}^{-1}$ from $1580 \mathrm{~cm}^{-1}$ peak and $2.31 \times 10^{-15} \mathrm{~m}^{2} \mathrm{~s}^{-1}$ from the $1600 \mathrm{~cm}^{-1}$ peak for $160{ }^{\circ} \mathrm{C}$.

\subsection{TGA curves}

TGA curves in Fig. 4 indicated that at $180{ }^{\circ} \mathrm{C}$ the remaining mass from DOP, PVC-DOP film and the film with LSN117 was 99,98 and $100 \%$, respectively. At $225{ }^{\circ} \mathrm{C}, 91,88$ and $97 \%$ of the initial mass of DOP, PVC-DOP film and the film with LSN117 remained, respectively. This shows that the PVC-LSN117 sample had minimum mass loss compared to the others in this temperature range.

\subsection{PVC degradation rate constants}

When PVC was heated, DOP evaporated from the surface and $\mathrm{HCl}$ evolved from thermal degradation was evaporated from the film as a gaseous product. DOP evaporation was assumed to be equal to the DOP

Table 2

Absorbances at $1580 \mathrm{~cm}^{-1}$ and $1600 \mathrm{~cm}^{-1}$ peaks of DOP in PVCLSN117 films for different heating temperatures and periods

\begin{tabular}{llll}
\hline Temperature $\left({ }^{\circ} \mathrm{C}\right)$ & Time $(\mathrm{min})$ & $A$ at $1580 \mathrm{~cm}^{-1}$ & $A$ at $1600 \mathrm{~cm}^{-1}$ \\
\hline Unheated & - & 0.32 & 0.48 \\
160 & 15 & 0.56 & 0.88 \\
160 & 105 & 0.08 & 0.08 \\
180 & 15 & 0.40 & 0.64 \\
180 & 105 & 0 & 0 \\
\hline
\end{tabular}


diffused to the surface of the film, by taking the diffusion coefficients as constant during the operation temperatures. The evaporated DOP quantity, $M_{t}$, can be determined as follows:

$M_{t}=M_{\infty}(4 / L) \sqrt{(D t / \pi)}$

where $M_{\infty}=0.37$ ( $37 \%$ of the film is DOP).

Furthermore, time values were taken from the onset temperature $\left(175^{\circ} \mathrm{C}\right)$ of DOP evaporation under dynamic heating conditions. The remaining mass of DOP at this temperature was $99.5 \%$. Thus, for $200{ }^{\circ} \mathrm{C}$, time $t_{1}$ was taken as $2.5 \mathrm{~min}$; for $210{ }^{\circ} \mathrm{C}$, time was $3.5 \mathrm{~min}$ and for $250{ }^{\circ} \mathrm{C}$, time was $7.5 \mathrm{~min}$ in the $M_{t}$ determination.

Finally conversion $(\alpha)$ was:

$\alpha=\left[\left(a-M_{t}\right) / 36.3\right]$

where $\alpha=$ (moles of $\mathrm{HCl}$ released)/(moles of $\mathrm{HCl}$ potentially to be released); fraction of dehydrochlorinated bonds to potential double bonds that would be formed by total dehydrochlorination of PVC, $a=$ total mass loss \% from TGA curve at temperature $T$ at time $t$. $M_{t}=$ mass of DOP evaporated at time $t ; 36.3$ is the maximum $\mathrm{HCl}$ percentage which can be evolved from the films with $37 \%$ DOP by dehydrochlorination.

The Arrhenius equation is

$k=A \mathrm{e}^{-(E a / R T)}$

Since the heating rate is $\beta=(\mathrm{d} T / \mathrm{d} t)$, Eq. (5) can be written as

$(\mathrm{d} \alpha / \mathrm{d} T)=(A / \beta) \mathrm{e}^{-(E a / R T)}(1-\alpha)^{n}$

By taking the natural logarithm of both sides we obtain

$\ln (\mathrm{d} \alpha / \mathrm{d} T)=\ln (A / \beta)-(E a / R T)+n \ln (1-\alpha)$

According to Shindo and Hirai [7], $n$ was assumed to be 1. Considering $n=1$ the activation energy and preexponential factor can be found.

By substituting Eq. (4) into Eq. (5), a linear relation can be plotted, where the $y$ axis is $\ln [(\mathrm{d} \alpha / \mathrm{d} T) /(1-\alpha)]$ and the $x$ axis is $1 / T$; the activation energy $E a$ and preexponential factor $A$ can then be calculated (Fig. 6).

For film with LSN117 $E a$ and $A$ were found as $58 \mathrm{~kJ}$ $\mathrm{mol}^{-1}$ and $185 \mathrm{~min}^{-1}$, respectively. So the rate constant for the film with $\mathrm{LSN} 117$ at $180{ }^{\circ} \mathrm{C}$ was $3.16 \times 10^{-5}$ $\min ^{-1}$. For control film (without LSN117) $E a$ and $A$ values were found to be $77 \mathrm{~kJ} \mathrm{~mol}^{-1}$ and $2.83 \times 10^{3}$ $\min ^{-1}$, respectively. So the rate constant at $180{ }^{\circ} \mathrm{C}$ was $2.89 \times 10^{-5} \mathrm{~min}^{-1}$ for PVC-DOP. Comparable dehydrochlorination rate constants were found for films with and without LSN117 at $180{ }^{\circ} \mathrm{C}$.

Gupta and Viswanath [8] found $E a$ as $90.1-366.5$ $\mathrm{kJ} \mathrm{mol}^{-1}$, Jimenez et al. [9] as $90-170 \mathrm{~kJ} \mathrm{~mol}^{-1}$, and Audouin et al. [10] as $103-151 \mathrm{~kJ} \mathrm{~mol}^{-1}$, respectively. In

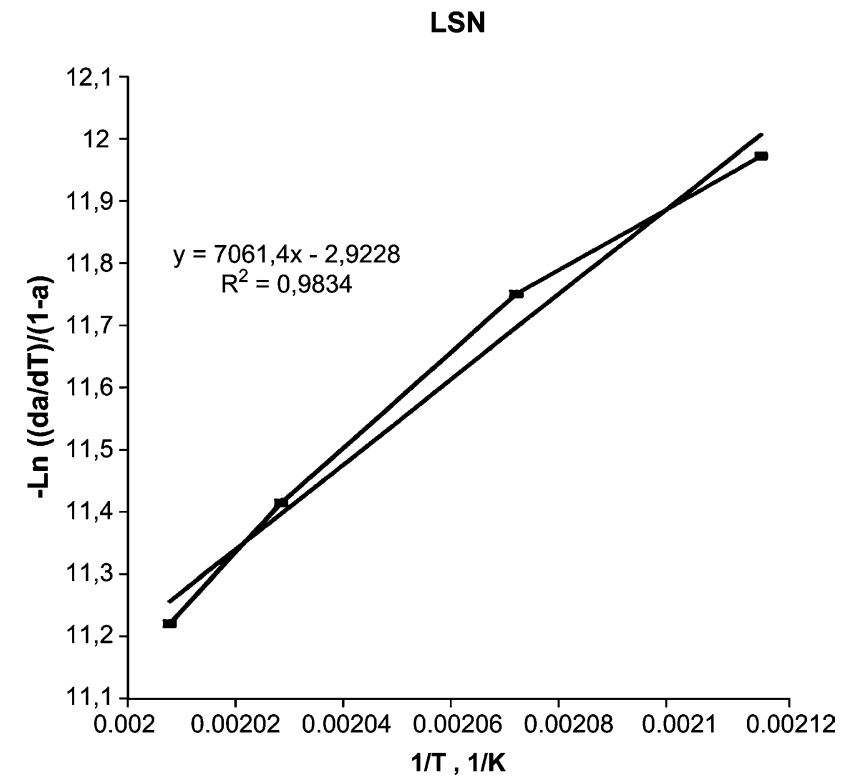

Fig. 6. Arrhenius curve for finding activation energy and preexponential factor.

this study the $E$ value of PVC dehydrochlorination was close to literature values. Analysis of TGA data indicated that LSN117 shifted the onset of dehydrochlorination temperature of PVC to higher temperatures, but once dehydrochlorination started, it occurred at a rate comparable with the control film.

On the other hand Martinez et al. [11] found the reaction constant, $k, 7.75 \times 10^{-5} \mathrm{~min}^{-1}$ at $180{ }^{\circ} \mathrm{C}$ for PVC. The lower rate constant obtained in present study indicated the PVC under study was more stable to heat than PVC studied by Martinez et al.

\section{6. $\mathrm{HCl}$ evolution from $\mathrm{PVC}$ and $\mathrm{PVC}$ with LSN117 films}

Fig. 7 shows $\mathrm{HCl}$ evolution from $\mathrm{PVC}$ and $\mathrm{PVC}$ with LSN117 films in PVC thermomat instrument at 140 and

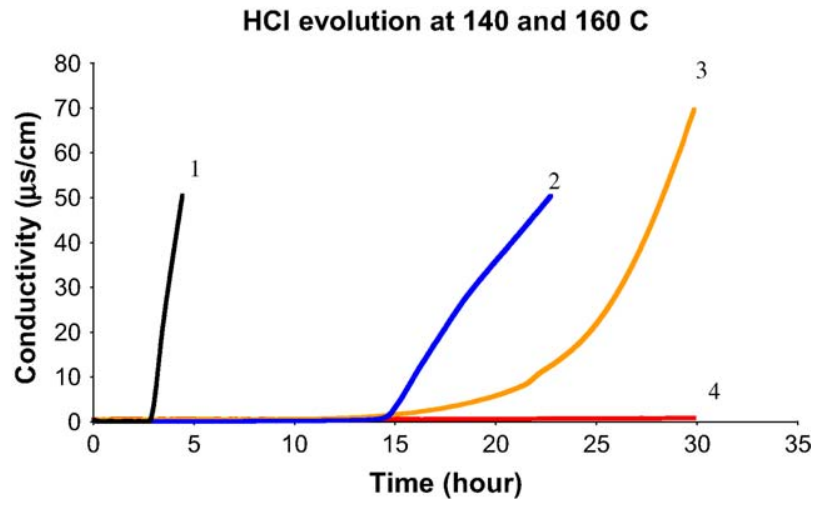

Fig. 7. $\mathrm{HCl}$ removal from films heated at $140{ }^{\circ} \mathrm{C}$ and $160{ }^{\circ} \mathrm{C}$; (1) $\mathrm{PVC}$ without LSN117 at $160{ }^{\circ} \mathrm{C}$; (2) PVC without LSN117 at $140{ }^{\circ} \mathrm{C}$; (3) PVC with LSN117 at $160{ }^{\circ} \mathrm{C}$; (4) PVC with LSN117 at $140{ }^{\circ} \mathrm{C}$. 


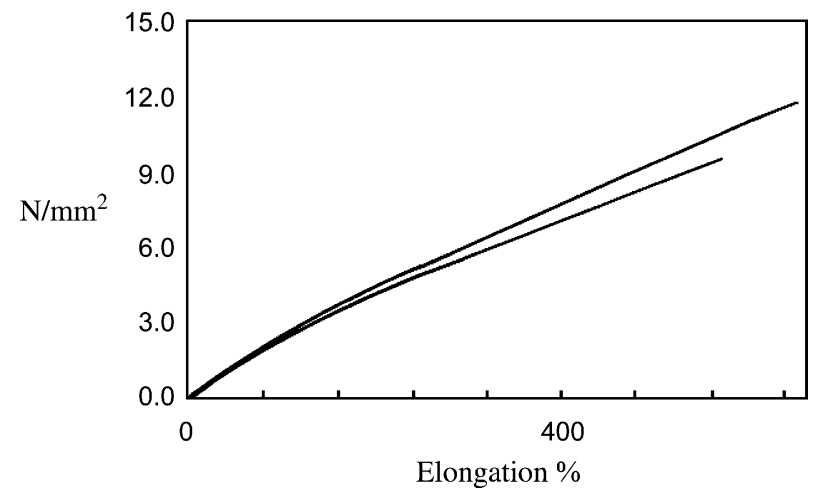

Fig. 8. Tensile strength and elongation at break of PVC film with LSN117.

$160{ }^{\circ} \mathrm{C}$, respectively. From this conductivity versus time diagram, it was observed that $\mathrm{HCl}$ evolution from PVC film without LSN117 starts to increase after a short induction time, $\mathrm{HCl}$ evolved from the $\mathrm{PVC}$ with LSN117 showed longer induction periods; at $140{ }^{\circ} \mathrm{C}$ no $\mathrm{HCl}$ was evolved from the film over the time of the experiment. $\mathrm{HCl}$ evolution from $\mathrm{PVC}$ increased with temperature, it was more rapid at $160{ }^{\circ} \mathrm{C}$ than at $140{ }^{\circ} \mathrm{C}$. The onset times for $\mathrm{HCl}$ evolution were 14.3 and $2.5 \mathrm{~h}$ at $140{ }^{\circ} \mathrm{C}$ and $160{ }^{\circ} \mathrm{C}$, respectively for PVC film without LSN117 On the other hand, the film with LSN117 did not evolve $\mathrm{HCl}$ in $30.3 \mathrm{~h}$ at $140{ }^{\circ} \mathrm{C}$. $\mathrm{HCl}$ started to evolve from the films with LSN 117 in $14.3 \mathrm{~h}$ at $160{ }^{\circ} \mathrm{C}$.

\subsection{Tensile strength and elongation at break}

From Fig. 8, average tensile strength and average elongation at break were found as $10.3 \mathrm{~N} \mathrm{~mm}^{-2}$ and $600 \%$, respectively for PVC film with LSN117 stabilizer. For PVC without additive these values were 13.3 $\mathrm{N} \mathrm{mm}{ }^{-2}$ and $330 \%$, respectively [12]. LSN 117 had no significant effect on tensile strength, but it increased the elongation at break.

\section{Conclusion}

The composition of the material was analysed by EDX analysis. Thermomat analysis showed that the addition of the organotin stabilizer retarded $\mathrm{HCl}$ evolution during heating. Since the organotin stabilizer was a liquid which was more miscible with PVC compared to solid heat stabilizers, it had a positive effect on retarding the $\mathrm{HCl}$ evolution in the beginning by reaching and replacing labile chlorine atoms in PVC.
A kinetic study was carried out using IR and TGA. Activation energies were close to the literature values. Whilst the mechanical strength was not much affected, LSN117 gives better elongation at break values than PVC-DOP film.

However, evaporation of DOP from plasticized PVC could not be hindered which would be the cause of fire in case of heating in air. Thus, further studies on plasticisers which are not volatile and organotin stabilizers should be conducted.

\section{Acknowledgements}

The authors acknowledge Akdeniz Kimya for supplying the samples of this study, Ege University Research Fund for giving financial support to this project with No. 98/MÜH/15, and TUBITAK MISAG 185 for PVC thermomat analysis.

\section{References}

[1] Wypych J. In: PVC stabilization. New York: Elsevier; 1986. p. 224-31.

[2] Haar GT, Othmer K. In: Encyclopedia of chemical technology, 14. New York: John Wiley and Sons; 1978. p. 196-200.

[3] Garrigues C, Guyot A, Tran VH. Thermal dehydrochlorination and stabilization of polyvinyl chloride in solution: Part VIII. Dialkyltin carboxylates: substitution reaction. Polym Degrad Stab 1994;43:299-306.

[4] Rujian X, Dafei Z, Seren Z. Effect of organotin stabilizer on the thermal stabilization of PVC: Part I - The influence of dibutyltin dilaurate on polyene sequences. Polym Degrad Stab 1989;27: 203-10.

[5] Arkis E, Balkose D. Tin soaps in emulsion PVC heat stabilization. Adv Polym Tech 2002;21:65-73.

[6] Baltacioglu H, Balkose D. Effect of zinc stearate and/or epoxidized soybean oil on gelation and thermal stability of PVC-DOP plastigels. J Appl Polym Sci 1999;74(10):2488-98.

[7] Shindo Y, Hirai T. Dehydrohalogenation of PVC in tetrahydrofuran solution with alcoholic KOH. Makromol Chem 1972;155: $1-16$.

[8] Gupta MC, Viswanath SG. Role of metal oxides in the thermal degradation of polyvinyl chloride. Ind Eng Chem Res 1998;37: 2707-12.

[9] Jimenez A, Berenguer V, Lopez J, Vilaplana J. New mathematical model on the thermal degradation of industrial plastisols. J Appl Polym Sci 1996;60:2041-8.

[10] Audouin L, Dalle B, Metzger G, Verdu J. Thermal aging of plasticized PVC 1. the weight loss kinetics in the PVCdidecylphthalate system. J Appl Polym Sci 1992;45:2091-6.

[11] Martinez JAG, Fernandez FG, Manley TR. The initial thermal stability of PVC. Br Polym J 1985;18:201-8.

[12] Arkis E. PhD thesis (supervised by Balkose D), Lead free PVC heat stabilizers. Ege University Graduate School of Applied and Natural Sciences, İzmir, 2000. 